Bangl. J. Vet. Med. (2008). 6 (1): 121-126

\title{
DETERMINATION OF MINIMUM INHIBITORY CONCENTRATION (MIC) OF CLOXACILLIN FOR SELECTED ISOLATES OF METHICILLIN-RESISTANT STAPHYLOCOCCUS AUREUS (MRSA) WITH THEIR ANTIBIOGRAM
}

\author{
M. A. Islam ${ }^{1}$, M. M. Alam ${ }^{1}$, M. E. Choudhury ${ }^{2}$, N. Kobayashi ${ }^{3}$ and M. U. Ahmed ${ }^{1 *}$ \\ ${ }^{1}$ Department of Medicine, ${ }^{2}$ Department of Pharmacology, Faculty of Veterinary Science, Bangladesh \\ Agricultural University, Mymensingh-2202, Bangladesh, ${ }^{3}$ Department of Hygiene, School of Medicine, Sapporo \\ Medical University, S-1, W-17, Chuo-ku, Sapporo 060, Japan \\ *Corresponding author's e-mail address: muzahedahmed@gmail.com
}

\begin{abstract}
The minimum inhibitory concentration (MIC) represents the concentration of antimicrobial at which there is complete inhibition of growth of organism. In order to determine the MIC of cloxacillin, 10 MRSA were previously detected from 40 clinical isolates of Staphylococcus aureus by polymerase chain reaction (PCR). Agar plate dilution test was used to determine the MIC of cloxacillin. The clinical samples were collected from Mymensingh Medical College Hospital, Mymensingh. The study was done in the Department of Medicine, Faculty of Veterinary Science, Bangladesh Agricultural University, Mymensingh from July 2006 to June 2007. The MIC of the cloxacillin for 5 MRSA strains were $\geq 32$ ( $\mu \mathrm{g} / \mathrm{ml}$ ), for $1 \mathrm{MRSA}$ strain was $\geq 128(\mu \mathrm{g} / \mathrm{ml})$ and for another 4 MRSA strains were above $\geq 128(\mu \mathrm{g} / \mathrm{ml})$. Antimicrobial susceptibility test of the isolated organisms were done by disc diffusion method. On antibiotic susceptibility test, MRSA strains showed $100 \%$ resistant against penicillin, oxacillin, cloxacillin and amoxycillin. Cent per cent susceptibility of MRSA was found against vancomycin, ciprofloxacin, erythromycin, fusidic acid and rifampicin.
\end{abstract}

Key words: Minimum inhibitory concentration (MIC), antibiotic resistance, cloxacillin, methicillin-resistant Staphylococcus aureus (MRSA)

\section{INTRODUCTION}

Staphylococcus aureus become resistant to many commonly used antibiotics due to indiscriminate use of antibiotics. Staphylococcal resistance to penicillin is mediated by penicillinase (a form of $\beta$-lactamase) production: an enzyme which breaks down the $\beta$-lactam ring of the penicillin molecule. First report of a penicillin-resistant strain of $S$. aureus was published in 1945, revealing its association with penicillinase enzyme produced by the bacteria (Spink and Ferris, 1945). The $\beta$-lactamase-resistant penicillins (methicillin, oxacillin, cloxacillin and flucloxacillin) were developed to treat penicillin-resistant S. aureus. Penicillinase-resistant penicillins are able to resist degradation by staphylococcal penicillinase and are still used as first-line treatment. Methicillin was the first antibiotic in this class and was introduced in 1959. But two years later, the first case of methicillin-resistant S. aureus (MRSA) was reported in England (Jevons,1961). The MRSA is a specific strain of the Staphylococcus aureus bacterium that has developed antibiotic resistance to all penicillins, including methicillin and other narrow-spectrum $\beta$-lactamase-resistant penicillin antibiotics (Foster, 1996). The resistant strain, MRSA which was first discovered in the UK in 1961, now is widespread, particularly in the hospital setting. MRSA may also be known as oxacillin-resistant Staphylococcus aureus (ORSA) and multiple-resistant Staphylococcus aureus. Despite this, MRSA generally remained an uncommon finding even in hospital settings until the 1990's when there was an explosion in MRSA prevalence in hospitals (Johnson et al., 2004). Worldwide, an estimated 2 billion people carry some form of S. aureus; of these, up to 53 million $(2.7 \%$ of carriers) are thought to carry MRSA. In the United States, 95 million carry S. aureus in their noses; of these 2.5 million (2.6\% of carriers) carry MRSA (Graham et al., 2006). 
MRSA was recognized as an important nosocomial infection in the U.S. in the late 1960s, and became endemic in human health care settings. The National Nosocomial Infections Surveillance System (NNIS) reports an increasing trend of MRSA. A 40\% increase in resistance was noted in 1999 compared to the results of 19941998 data (NNIS, 2000). MRSA accounts for $52.3 \%$ of S. aureus nosocomial infections (NNIS, 2000). MRSA is now endemic in many hospitals, and is one of the leading causes of nosocomial pneumonia and surgical site infection and the second leading cause of nosocomial blood stream infections (Boyce et al., 1994).

Antimicrobial resistances of bacterial pathogens are a major problem for the treatment of animal and human patients with bacterial diseases. Determination of MIC of antibiotics for bacteria plays a crucial role for determination of antibiotic resistance of bacteria. The present research work was undertaken for determining resistance of Staphylococcus aureus against commonly used antibiotics.

\section{MATERIALS AND METHODS}

The study was done in the Department of Medicine, Faculty of Veterinary Science, Bangladesh Agricultural University, Mymensingh from July 2006 to June 2007.

\section{Determination of MIC by agar plate dilution method}

Agar plate dilution test was used to determine the Minimum Inhibitory Concentration (MIC) of an antimicrobial agent.

\section{Preparation of antimicrobial agents}

Individual antibiotics were dissolved in solvents (water) and diluents (water) and then added to molten agar. Dilutions of antimicrobial agents were prepared in sterile distilled water at 10X concentration. The MIC range varied with different drugs. All MIC range was followed according to the NCCLS guidelines (NCCLS, 1997).

\section{Preparations of plates}

$100 \mathrm{ml}$ Mueller-Hinton medium of each flask was autoclaved and allowed to cool at $50^{\circ} \mathrm{C}$ in water bath. Appropriate volume of intermediate antimicrobial concentration was added to each flask at $10 \mathrm{X}$ concentration, mixed thoroughly and antibiotic-containing media was poured immediately on the plate. Two fold $\left(\log _{2}\right)$ serial dilutions of the antimicrobial were added with agar medium according to Washington and Wood (1995). The concentration of the cloxacillin in different plates was $128 \mu \mathrm{g} / \mathrm{ml}, 64 \mu \mathrm{g} / \mathrm{ml}, 32 \mu \mathrm{g} / \mathrm{ml}, 16 \mu \mathrm{g} / \mathrm{ml}, 8 \mu \mathrm{g} / \mathrm{ml}, 4$ $\mu \mathrm{g} / \mathrm{ml}, 2 \mu \mathrm{g} / \mathrm{ml}, 1 \mu \mathrm{g} / \mathrm{ml}$.

\section{Inoculum preparation for MIC test}

Inocula were obtained from an overnight agar culture of the test organism. Inoculum for the MIC test was prepared by taking at least three to five well-isolated colonies of the same morphology from an agar plate culture. The top of each colony was touched with a sterile loop and the growth was transferred into a tube containing 4 to $5 \mathrm{ml}$ of normal saline. The broth culture was incubated at $35^{0} \mathrm{C}$ until it achieved the turbidity of the $0.5 \mathrm{McF}$ arland standards (usually 2 to 6 hours). This results in a suspension containing approximately 1 to $2 \times 10^{8} \mathrm{cfu} / \mathrm{ml}$. The turbidity of the actively growing broth culture was adjusted with sterile broth to obtain turbidity comparable to that of the $0.5 \mathrm{McF}$ arland standards.

\section{Turbidity standard for MIC inoculum preparation}

To standardize the inoculum density for a susceptibility test, $\mathrm{BaSO}_{4}$ turbidity standard, equivalent to a 0.5 McFarland standards was used. A 0.5 McFarland standard was prepared as described in NCCLS (NCCLS, 1997). One percent V/V solution of sulfuric acid was prepared by adding $1 \mathrm{ml}$ of concentrated sulfuric acid to 99 $\mathrm{ml}$ of water and mixed well. A $1.175 \% \mathrm{~W} / \mathrm{V}$ solution of barium chloride was prepared by dissolving $2.35 \mathrm{~g}$ of dehydrated barium chloride $\left(\mathrm{BaCl}_{2} \cdot \mathrm{H}_{2} \mathrm{O}\right)$ in $200 \mathrm{ml}$ of distilled water. To make the turbidity standard, $0.5 \mathrm{ml}$ of the barium chloride solution was added to $1 \% 99.5 \mathrm{ml}$ sulfuric acid solution and mixed well. A small volume of those turbid solutions was transferred to a screw-capped tube of the same type as used for preparing the control inocula and stored in the dark at room temperature. 


\section{Inoculation and incubation of the medium}

Agar surface of the plates containing different concentration of antimicrobial agent and the control plate without antimicrobial agent were spot inoculated with a $2 \mu \mathrm{l}$ suspension under digital micropipette. Inoculation was done from the plate containing lowest concentration of antimicrobial and the control plate was inoculated lastly. Inoculated agar plates were allowed to stand until the inoculum spot were completely absorbed and after then it was incubated at $35^{\circ} \mathrm{C}$ for overnight.

\section{Interpretation of results}

The MIC represents the concentration of antimicrobial at which there is complete inhibition of growth. In reading the end points, a barely visible haze of growth or a single colony is disregarded. The results were interpreted according to the recommendation chart of NCCLS (NCCLS, 1997). The strains were referred to as Resistant (R) and Susceptible (S) in relation to the MIC of antimicrobial tested as per Table 1.

Table 1. Zone diameter interpretative standards and equivalent minimum inhibitory concentration (MIC) breakpoints for isolated bacteria

\begin{tabular}{|c|c|c|}
\hline \multirow[t]{2}{*}{ Name of antibiotic } & \multicolumn{2}{|c|}{ MIC value $(\mu \mathrm{g} / \mathrm{ml})$} \\
\hline & Susceptible (S) & Resistant (R) \\
\hline Cloxacillin & $\leq 2$ & $\geq 4$ \\
\hline
\end{tabular}

\section{Antimicrobial susceptibility test}

Antimicrobial susceptibility test of the isolated organisms was done by disc diffusion method using the KirbyBauer technique (Bauer RW et al., 1966) and as per recommendation of NCCLS (NCCLS, 1997). Panel of antibiotics were used (Table 3). All tests were performed on Mueller-Hinton agar. The surface was lightly and uniformly inoculated by cotton swab. Prior to inoculation, the swab stick was dipped into bacterial suspension having visually equivalent turbidity to $0.5 \mathrm{McF}$ arland standards. The swab stick was then took out and squeezed on the wall of the test tube to discard extra suspension. Inoculated plates were incubated at $35^{\circ} \mathrm{C}$ for 24 hours. On the next day, plates were read by taking measurement of zone of inhibition. Results were recorded and graded as Resistant (R) and Sensitive (S) according to the reference zone of inhibition of particular antibiotic (Fig. 1). Known control strain (ATCC 25923) was used for quality control. The zone of inhibition were interpretated by antibiotic zone size interpretative chart as recommended by NCCLS and were categorized into two groups, namely sensitive (S) and resistant (NCCLS, 1997).

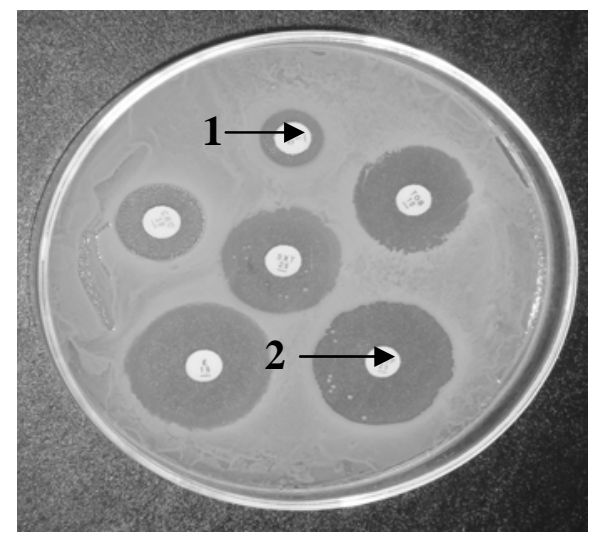

Fig. 1. Mueller Hinton agar media with antibiotic sensitivity disc showing oxacillin resistant (arrow ' 1 ' indicator disc) and amoxycillin sensitive (arrow ' 2 ' indicator disc). 


\section{RESULTS AND DISCUSSION}

Multiple antimicrobial resistances of the bacterial pathogens are of great concern both in veterinary and human medicine worldwide. Antimicrobial resistance is a serious problem in the treatment of animal and human patients with infectious diseases. Like other bacterial pathogens Staphylococcus aureus has become resistant to many antimicrobials through the acquisition of mobile drug resistance genes. A major force in the overexpression of endogenous multidrug transporters and spread of plasmid encoded multidrug transporters in the huge consumption of antibiotics in human therapy, animal husbandry and agriculture. Now at the beginning of third millennium we have been forced to limit our therapeutic options in order to combat these insidious enemies.

MRSA represents a major challenge to hospitals in all countries due to the emergence and spread of isolates with decreased susceptibilities to several antibiotic classes, in addition to methicillin and the other members of the $\beta$-lactam family. Molecular typing techniques applied to international collections of MRSA isolates have contributed to the understanding of the epidemiology and evolution of this infectious agent.

MRSA has become increasingly prevalent worldwide. Strengthening surveillance and screening of high-risk patients appears as an important component of effective infection control programme to limit the spread of MRSA in hospitals. In this context accurate detection of MRSA is essential. Antimicrobial susceptibility by disc diffusion or broth microdilution methods cannot detect MRSA those express low levels of oxacillin resistance. Recently many methods for detection of MRSA have been evaluated and are widely used in bacteriological laboratory. Measurement of minimum inhibitory concentration (MIC) of antibiotics is an important aid to determine antibiotic resistance to bacteria. If MIC of oxacillin and cloxacillin are $\geq 4 \mu \mathrm{g} / \mathrm{ml}$ then the $S$. aureus is considered as oxacillin and cloxacillin resistant S. aureus (NCCLS, 1992).

The MIC of cloxacillin of MRSA were shown in the Table 2. Most of the MRSA strains showed growth in a concentration of $\geq 16 \mu \mathrm{g} / \mathrm{ml}$ while the breakpoint of cloxacillin is $\leq 2$ to $\geq 4$ (Table 1) which indicates that the strains were highly resistant against cloxacillin.

Table 2. The minimum inhibitory concentration (MIC) of the cloxacillin of MRSA strains

\begin{tabular}{|c|c|c|c|c|c|c|c|c|}
\hline \multirow{2}{*}{$\begin{array}{l}\text { Sample } \\
\text { number }\end{array}$} & \multicolumn{8}{|c|}{ Dilution of cloxacillin $(\mu \mathrm{g} / \mathrm{ml})$} \\
\hline & $\geq 128$ & $\geq 64$ & $\geq 32$ & $\geq 16$ & $\geq 8$ & $\geq 4$ & $\geq 2$ & $\geq 1$ \\
\hline 17 & - & - & - & + & + & + & + & + \\
\hline 23 & + & + & + & + & + & + & + & + \\
\hline 39 & - & - & - & + & + & + & + & + \\
\hline 43 & - & - & - & + & + & + & + & + \\
\hline 55 & - & + & + & + & + & + & + & + \\
\hline 82 & - & - & - & + & + & + & + & + \\
\hline 88 & + & + & + & + & + & + & + & + \\
\hline 90 & + & + & + & + & + & + & + & + \\
\hline
\end{tabular}

'+'indicates growth of bacteria (resistant to cloxacillin), '-'indicates inhibition of growth of bacteria (sensitive to cloxacillin).

Antibiotic resistance in bacteria evolves by mutations in the bacterium's genes, by rearrangement of the bacterium's genes, or by acquisition of genes that result in antibiotic resistance from other bacteria. The mechanism of resistance to methicillin is by the acquisition of the mecA gene, which codes for an altered penicillin-binding protein (PBP) that has a lower affinity for binding $\beta$-lactams (penicillins, cephalosporins and carbapenems). This confers resistance to all $\beta$-lactam antibiotics. If the bacteria produces the enzymes $\beta$ lactamase or penicillinase, these enzymes will break open the $\beta$-lactam ring of the antibiotic, rendering the antibiotic ineffective.Glycopeptide resistance is mediated by acquisition of the van $A$ gene. The van $A$ gene originates from the enterococci and codes for an enzyme that produces an alternative peptidoglycan to which vancomycin will not bind. 
Antibiotic resistance pattern of MRSA $(n=10)$ isolates were shown in Table 3. All MRSA isolates in this study appeared sensitive to vancomycin, ciprofloxacin, erythromycin, fusidic acid and rifampicin. MRSA were resistant to cefuroxin $(20 \%)$, ceftriaxone $(20 \%)$, cephradine $(40 \%)$ and penicillin $(100 \%)$, oxacillin $(100 \%)$, amoxycillin (100\%) and cloxacillin (100\%). MRSA become resistant to beta-lactam antibiotics due to mutation in PBP gene (Matsuhashi et al., 1986) but resistance to other antibiotics is not well elucidated as yet. The probable reason behind this resistance should be ribosomal mutation. Vancomycin intermediate (VISA) and resistant (VRSA) strains of $S$. aureus already reported in many countries (CDC, 2002). Strains of MRSA used in this study were not resistant to erythromycin, ciprofloxacin, fusidic acid, rifampicin and vancomycin.

Table 3. Antibiogram of MRSA strains $(n=10)$

\begin{tabular}{|lll|}
\hline Antibiotics & Resistant & Sensitive \\
\hline Penicillin & $10(100 \%)$ & $0(0 \%)$ \\
Oxacillin & $10(100 \%)$ & $0(0 \%)$ \\
Amoxycillin & $10(100 \%)$ & $0(0 \%)$ \\
Cloxacillin & $10(100 \%)$ & $0(0 \%)$ \\
Cephradine & $4(40 \%)$ & $6(60 \%)$ \\
Ceftriaxone & $2(20 \%)$ & $8(80 \%)$ \\
Cefuroxin & $2(20 \%)$ & $8(80 \%)$ \\
Erythromycin & $0(0 \%)$ & $10(100 \%)$ \\
Ciprofloxacin & $0(0 \%)$ & $10(100 \%)$ \\
Fusidic acid & $0(0 \%)$ & $10(100 \%)$ \\
Rifampicin & $0(0 \%)$ & $10(100 \%)$ \\
Vancomycin & $0(0 \%)$ & $10(100 \%)$ \\
\hline
\end{tabular}

\section{ACKNOWLEDGEMENT}

The authors greatly thankful to BAURES, BAU, Mymensingh for financial assistance to complete the work.

\section{REFERENCES}

1. Bauer RW, Kirby MDK, Sherris JC, Turck M (1966). Antibiotic susceptibility testing by standard single disc diffusion method. American Journal of Clinical Pathology 45: 493-496.

2. Boyce JM, Jackson MM, Puqliese G, Batt MD, Fleming D, Garner JS, Hartstein AI, Kauffman CA, Simmons M and Weinstein R (1994). Methicillin-resistant Staphylococcus aureus (MRSA): a briefing for acute care hospitals and nursing facilities. The AHA Technical Pannel on Infections Within Hospitals. Infection Control and Hospital Epidemiology 15: 105-115.

3. CDC (2002). Staphylococcus aureus resistant to vancomycin - United States, 2002. Morbidity and Mortality Weekly Report 51: 565-567.

4. Foster T (1996). Staphylococcus. In: Barron's Medical Microbiology. Barron S, Teake RC, James DA, Susman M, Kennedy CA, Singleton MJD and Schuenke S (eds), $4^{\text {th }}$ edn., University of Texas Medical Branch, Galveston, USA.

5. Graham P, Lin S, and Larson E (2006). A U.S. population-based survey of Staphylococcus aureus colonization. Annals of Internal Medicine 144: 318-325.

6. Jevons MP (1961). Celbenin-resistant staphylococci. British Medical Journal 1: 124-125.

7. Johnson AP, Aucken HM, Cavendish S, Ganner M, Wale MC and Warner M (2004). Dominance of EMRSA-15 and-16 among MRSA causing nosocomial bacteraemia in the UK: analysis of isolates from the European Antimicrobial Resistance Surveillance System (EARSS). Journal of Antimicrobial Chemotherapy 48: 143-144.

8. Matsuhashi M, Song MD, Ishino F, Wachi M, Doi M and Inoue M (1986). Molecular cloning of the gene of a penicillinbinding protein supposed to cause high resistance to $\beta$-lactam antibiotics in Staphylococcus aureus. Journal of Bacteriology 167: 975-980.

9. NCCLS (1992). Methods for dilution antimicrobial susceptibility tests for bacteria that grow aerobically. $2^{\text {nd }}$ edn., Approved Standard. NCCLS Document M7-A2 (M100-S4).

10. NCCLS (1997). Performance Standards for Antimicrobial Disk Susceptibility Tests: Approved Standard M2-A7. National Committee for Clinical Laboratory Standards, Wayne, PA, USA. 
11. NNIS (2000). System Report, Data Summary from January 1992-Aprill 2000. American Journal of Infection Control 28: 429-448.

12. Spink WW and Ferris V (1945). Quantitative action of penicillin inhibitor from penicillin-resistant strain of Staphylococcus. Science 102: 102-221.

13. Washington JA and Wood GL (1995). Antimicroibial susceptibility tests: Dilution and disc diffusion methods. In: Manual of Clinical Microbiology. 1327-1331. 